\title{
Rios urbanos e suas adversidades: repensando maneiras de ver as cidades
}

\section{Urban rivers and their adversities: rethinking ways to see the city}

\author{
Bruno Capilé \\ Universidade Federal do Rio de Janeiro \\ brcapile@gmail.com \\ Rio de Janeiro \\ Brasil
}

Recibido: 23 de mayo de 2015

Aprobado: 12 de agosto de 2015

\section{RESUMO}

0 presente texto não é uma proposta de uma narrativa específica, mas sim de reflexões teóricas e metodológicas sobre 0 que significa conceber os rios urbanos, seus fluxos e diálogos através da cidade, assim como a apropriação social destes, de modo a desafiar a clássica dicotomia sociedade-natureza. A perspectiva da história ambiental, com a colaboração de diferentes disciplinas, é essencial para desconstruir, ao menos em parte, tal dicotomia. Ou seja, as contribuições de áreas como geografia, ecologia, e até mesmo literatura, permitem estabelecer conexões mais complexas e ricas que "costuram" essas duas entidades, que têm sido comumente separadas disciplinarmente pelas ciências da natureza e ciências sociais.

\section{PALAVRAS-CHAVE}

Rios urbanos, história ambiental, cidade.

\section{ABSTRACT}

This text is not a proposal for a specific narrative, but for theoretical and methodological reflections on what it means to conceive urban rivers: their flow and dialog across the city, as well as their social appropriation in order to challenge the classic dichotomy between society and nature. Environmental History, with the collaboration of different disciplines, is essential to de-construct this dichotomy, at least partially. Contributions from areas such as Geography, Ecology, and even Literature can establish more complex and rich connections to "tailor" these two entities, which have been commonly separated in Natural Sciences and Social Sciences.

\section{KEYWORDS}

Urban rivers, environmental history, city.

\begin{abstract}
A circulação de água produz uma geografia física e uma paisagem material, mas também uma paisagem simbólica e cultural de poder(...); A conquista ecológica da água torna-se, portanto, um atributo necessário para 0 crescimento e expansão da cidade. (Erik Swyngedouw - A cidade como um híbrido) ${ }^{1}$
\end{abstract}

A cidade flui - em trânsito, em pessoas, em energia, e também em água. Muito já se passou desde que os estudos meticulosos sobre circulação sanguínea de William Harvey influenciaram toda uma geração de

\footnotetext{
${ }^{1}$ Swyngedouw, Erik. A cidade como um híbrido: natureza, sociedade e "urbanização-cyborg". In Henri Acselrad (org.) $A$ duração das cidades: sustentabilidade e risco nas políticas urbanas. Rio de Janeiro: DP\&A Editora, 2001.
} 
profissionais que pensavam sobre a urbanidade nos séculos XVIII e XIX, dando grande destaque para os itinerários das águas urbanas no abastecimento e no saneamento. ${ }^{2} 0$ manuseio da palavra água propicia construir narrativas que conectam um coletivo de interações que outros termos semelhantes não poderiam. Isso explica, em parte, a escolha pelo estudo de rios urbanos, enquanto entidades, e não da circulação sugerida por Erik Swyngedouw, ${ }^{3}$ que optou por uma arguição centralizada essencialmente na água. 0 presente texto não é uma proposta de uma narrativa específica, mas sim de reflexões teóricas e metodológicas sobre o que significa conceber os rios urbanos, seus fluxos e diálogos através da cidade, assim como a apropriação social destes, de modo a desafiar a clássica dicotomia sociedade-natureza. A perspectiva da história ambiental, com a colaboração de diferentes disciplinas, é essencial para desconstruir, ao menos em parte, tal dicotomia. Ou seja, as contribuições de áreas como geografia, ecologia, e até mesmo literatura, permitem estabelecer conexões mais complexas e ricas que "costuram" essas duas entidades, que têm sido comumente separadas disciplinarmente pelas ciências da natureza e ciências sociais.

A cidade é o melhor exemplo de como forças antrópicas, de transformar o próprio ambiente em que vive, está intrinsecamente conectado com as diferentes maneiras do ser humano reconstruir a si mesmo, ${ }^{4}$ e também de como a transformação do ambiente urbano gera novos tipos de relações. Tendo isso em vista, e na atual demanda socioambiental de evidenciar nossa necessidade e nossas interlocuções através da natureza, elaboramos nesse texto, uma discussão sobre narrativas que contemplem as complexas interações entre a cidade e 0 ambiente biofísico, em particular sobre os rios urbanos do Rio de Janeiro na virada para o século XX. Este foi um momento em que os processos de urbanização e crescimento industrial, que suscitaram e intensificaram novos meios de usar e ocupar as bacias hidrográficas destes rios, foram evidenciados desde as partes mais altas dos vales do maciço da Tijuca até as zonas litorâneas mais centrais. Nossa proposta é considerar os rios e sua influência na sociedade carioca, e afirmá-Ios como fatores essenciais na dinâmica e no desenvolvimento da cidade, com mediações múltiplas e complexas. Ou seja, examinar tanto o papel dos rios nos processos urbanos da cidade do Rio de Janeiro, quanto o impacto desta urbanização sobre os rios.

Ao investigar a história das relações entre natureza e sociedade nesse âmbito, considera-se que os rios urbanos são integrantes, ativos e dinâmicos, da paisagem urbana. Dentre essas relações estão as transformações, antropogênica ou não, nos rios que desempenharam importantes papéis no crescimento da cidade. Ora, se quisermos incorporar em nossas análises tais modificações e associações que ocorreram em, e por causa de, os rios, isto nos obriga a vê-los de uma maneira não isolada - ou somente o fluxo superficial de água - mas como parte da categoria geográfica de bacia hidrográfica - 0 que incluem afluentes e área de drenagem. Agregar interdisciplinarmente conceitos de outras áreas significa que ainda mantemos forte dependência de análises historiográficas, e que reinterpretar e transpor essas considerações para esse tipo de análise permite observar a relação urbana no contexto de sua interação com os sistemas hídricos. ${ }^{5}$ É pela bacia que o fluxo dos rios entra no sistema ambiental urbano funcionando como abastecimento de água, escoamento de dejetos, oferta de energia hidráulica, ${ }^{6}$ da mesma forma que funcionou como área de encontro e de lazer, beleza cênica, em diferentes apropriações sociais. Por tanto, percebemos que analisar os rios urbanos como bacias - seguindo a dimensão social da cidade e ambiental dos sistemas hídricos, e as interseções entre estas - faz mais sentido numa proposta de história ambiental urbana. Por tanto, ao escolhê-las incluímos também os vales, as florestas, os pântanos, restingas e mangues, desde as nascentes no maciço da Tijuca até a foz destes rios na praia do Flamengo, na Lagoa Rodrigo de Freitas, na enseada de Botafogo e no antigo manguezal de São Diogo, atual Canal do Mangue.

\footnotetext{
${ }^{2}$ Sennett, Richard. Carne e Pedra: o corpo e a cidade na civilização ocidental. São Paulo: ed. Record, 2003.

Swyngedouw, Erik. Metabolic urbanization: the making of cyborg cities. In Nikolas Heynen, Maria Kaika, Erick Sweyngedouw (eds). In the nature of cities: urban political ecology and the politics of urban metabolismo. New York: Routledge Press, 2006.

${ }^{3}$ Swyngedouw, op. cit.

${ }^{4}$ Park, Robert. On Social Control and Collective Behavior. Chicago: University of Chicago Press, 1967.

${ }^{5}$ Miraglia, Marina. "La Historia Ambiental y los Sistemas Complejos em el Estudio de los Procesos de Construcción Territorial em las Cuencas Hidrográficas: Caso de Estudio en la Provincia de Buenos Aires. Republica Argentina." In Eunice Nodari, João Klug. História Ambiental e Migrações. São Leopoldo: Oikos, 2012.

${ }^{6}$ Herrero, Ana C. Desarrollo Metodológico para el Análisis del Riesgo Hídrico Poblacional Humano en Cuencas Periurbanas: Caso de Estudio: Arroyo Las Cantonas, Región Metropolitana de Buenos Aires. Tese de doutorado da Facultad de Ciencias Exactas y Naturales da UBA. 2006.
} 
0 aprofundamento na investigação sobre e através destas bacias hídricas, com seus rios e vales, permite esclarecer realidades históricas conjunturais existentes dentro de processos sociais já conhecidos, e ressignificáIos, como: crescimento demográfico e industrial, grandes obras públicas, usos locais dos rios por moradores próximos. Nossa análise ressalta esses processos integrados diretamente a esses rios, como 0 crescimento urbano e industrial e a dependência do abastecimento d'água, as grandes obras públicas que visava melhoramentos para a cidade, a complexa relação entre a população local e esses corpos d'água. Ou seja, quando olhamos para a história destes rios, estamos na realidade olhando para a história das relações deles com a sociedade carioca, a partir de fontes e leituras de eventos como: aterros e drenagens para construções; canalizações para oferta de água ou para escoamento de dejetos; pontes que propiciaram a expansão urbana para a região; enchentes e deslizamento de terras; secas e deficiência no abastecimento de água; barragens para a utilização das águas para a mobilização dos moinhos e turbinas das indústrias, ou o resfriamento dos seus diversos maquinários; uso dos rios pela população local para pesca, lazer, transporte, banho.

É preciso esquadrinhar uma abordagem que permita aprofundar em objetos e processos específicos e apresentar novas realidades e reflexões, o que colabora com novos entendimentos sobre a sociedade carioca em seu ambiente no passado. Para isso é fundamental abrir o terreno para uma discussão sobre os termos natureza e sociedade, com base nas contribuições da história ambiental.

\section{Perspectivas e narrativas sobre a dicotomia natureza-sociedade no ambiente urbano}

A assimetria entre natureza e cultura torna-se então uma assimetria entre passado e futuro. 0 passado era a confusão entre as coisas e os homens; o futuro, aquilo que não os confundirá mais (Bruno Latour, Jamais Fomos Modernos) ${ }^{7}$

Somos seletivos. Não podemos olhar para tudo. Escolhemos e montamos nossa realidade em prol de sentido, significado. Da mesma forma o historiador também é seletivo ao esboçar uma reconstrução de um passado, uma narrativa, a partir de suas escolhas. As escolhas do historiador são uma das grandes conexões entre o presente e o passado "resgatado", construído. Elas são o terreno onde nossas vontades se mesclam com nossas necessidades, onde buscamos o propósito em nossas atividades quando olhamos através do tempo. As escolhas podem ser "materializadas" por meio de perguntas, e a partir destas a pesquisa se desenrola. Portanto, quando utilizamos rios urbanos, e não da conquista urbana da água ou da circulação desta na cidade, vejo também aspectos diversos do próprio ambiente, que provavelmente não estariam no manejo discursivo da palavra água. Assim eu olho para as pedras nos rios, os pescadores, os acidentes no relevo, a erosão, os banhistas, os sedimentos em suspensão, as pontes, os engenheiros, o ciclo de cheias e secas, a topografia, bem como tantos outros elementos da complexa paisagem fluvial urbana.

Os diferentes significados possuem, por sua vez, diferentes histórias e complexidades. Ou seja, o termo natureza possui "uma quantidade extraordinária da história humana". ${ }^{8}$ E nesse passado é possível observar que 0 isolamento da natureza está intimamente ligado com a noção de negação do humano, do cultural, do social. Essa ideia de natureza intocada, remota, abstrata do homem, distorce e perturba as noções da intervenção humana nela. Passa a reforçar a dicotomia natural versus social que também se reflete como vemos as cidades, em particular 0 anseio pelo campo que surge no romantismo inglês pós-revolução industrial - como se o próprio campo não fosse antropizado, consumível. ${ }^{9}$ A própria separação entre sociedade e natureza tem sido uma consequência de uma interação cada vez mais intensa entre esses dois "polos". Nesse sentido, "falar do homem "intervindo" no processo natural implica na suposição de que ele possa crer não ser possível fazê-lo, ou possa decidir não fazê-

\footnotetext{
${ }^{7}$ Latour, Bruno. Jamais Fomos Modernos: Ensaio de Antropologia Simétrica. Rio de Janeiro: Ed. 34, 1994.

${ }^{8}$ Williams, Raymond. Ideias sobre a natureza. In Cultura e Materialismo, 89. São Paulo: Ed. UNESP, 2011.

${ }^{9}$ Thomas, Keith. O homem e o mundo natural: mudanças de atitude em relação às plantas e aos animais (1500-1800). São Paulo: Companhia das Letras, 2010.
} 
IO". ${ }^{10} \mathrm{E}$, conceber um espaço onde ocorre intervenção humana - não-natural - diferenciado de outro com baixa ou nenhuma intervenção - natural - permite uma narrativa onde a ação sobre a natureza se reduz a riqueza, recurso, desconsiderando suas forças naturais, sua diversidade, sua multiplicidade, sua beleza. Onde na realidade o que tem ocorrido cada vez mais intensamente é que estamos fundindo nossas forças sociais com as naturais de tal maneira que vale conceber nessa narrativa que tanto nós quanto 0 ambiente urbano somos produtos desta fusão. ${ }^{11}$

Um pressuposto que permeia as considerações do presente texto é a de que o ser humano não existe sem a dimensão da natureza, seja ela exterior a ele (água das chuvas, calor do sol, plantas alimentares, etc.) ou mesmo interior (calor humano, populações de bactérias benéficas ao nosso organismo, etc.). Essa mistura de elementos permite uma narrativa mais honesta e sofisticada. Uma construção textual que atenda à perspectiva do ser humano através da natureza, e jogue uma luz sobre 0 entendimento das ações e reações de nós mesmos, que dificilmente poderia ser percebidò de outra forma. Imaginemos, por exemplo, quando formos elaborar a história das faltas d'água na segunda metade do século XIX. Devemos considerar tanto o histórico de baixa pluviosidade relatado nas observações meteorológicas efetuadas pelo Imperial Observatório Astronômico no Rio de Janeiro, que acarretou em rios menos volumosos, quanto as ações humanas de desmatamento, para lenha e plantio de cafezeiros, e ocupação da terra, que prejudicaram a capacidade da floresta e sua bacia de reter água para os cursos fluviais. Devemos também observar as dificuldades e reações da população para obter água. Podemos inclusive explorar aspectos culturais do imaginário social urbano como, por exemplo, os miasmas causadores de doenças expelidos pelos mangues cariocas. Aqui o histórico de despejo de esgoto humano e industrial (matadouros e fábricas) prejudicou a circulação natural de água e sedimentos na foz dos rios criando um ambiente pútrido propício para doenças contagiosas. ${ }^{12} \mathrm{Na}$ realidade, 0 próprio ambiente fluvial possui características que tornam esse cenário mais severo, já que a parte do rio mais perto de sua foz apresenta baixa circulação de água e a concentração de tudo o que foi despejado nas partes superiores. Mas não podemos deixar de observar, também, que a teoria dos miasmas, embora fundamentada pela ciência da época, abriu caminho para a ampliação do espaço urbano mediante aterros e grandes obras públicas. Outro aspecto cultural, que também não deve ser deixado de fora da análise, é a depreciação e criminalização de grupos sociais que habitaram os mangues poluídos do final do século XIX. Os discursos de higienização e civilização justificaram o desalojamento de milhares de pessoas e seus hábitos locais nas desembocaduras dos rios urbanos, que já não eram vistos como naturais. Ou seja, a dinâmica do fluxo do rio incentiva o desenvolvimento e a aceitação de teorias higienistas no período, enquanto estas teorias também vão afetar o fluxo do rio. A escrita histórica tem uma posição de destaque no desenrolar dessa dinâmica conjunta entre natureza e sociedade, e também a "saúde" de ambas, permitindo maiores esclarecimentos sobre as transformações em ambientes degradados.

A simples escolha de uma palavra, em prol de outra de sentido similar, está imbricada com nossa posição frente ao objeto de estudo e pode ser responsável por narrativas totalmente diferentes. De maneira semelhante, a apropriação diferenciada de uma mesma palavra pode fornecer conclusões opostas. William Cronon ${ }^{13}$ estudando o papel de narrativas de histórias ambientais, analisa duas obras, publicadas no mesmo ano, com fontes semelhantes, sobre o mesmo assunto - as catastróficas tempestades de areia chamadas Dust Bowl-, porém com resultados completamente antagônicos. Para um dos autores - Paul Bonnifield -, o termo "natureza" era algo limitante a ser superado pelo esforço civilizatório da humanidade, uma história de triunfo da sociedade sobre os desastres naturais. Já para o segundo autor - 0 historiador ambiental Donald Worster, o qual iremos comentar um pouco mais adiante -, a mesma palavra considerava o episódio como fracasso dos seres humanos devido ao fato de não se adaptarem aos ciclos climáticos do ambiente semiárido, ocasionando tais tempestades. Para Cronon, um dos aspectos da prática historiográfica, a qual a história ambiental tem se ocupado em realizar, é buscar fazer

\footnotetext{
${ }^{10}$ Williams, 100.

${ }^{11}$ Williams, 100; Arnold, David. The problem of nature: environment, culture and European expansion. (New Perspectives on the Past). Oxford: Blackwell, 1996.

${ }^{12}$ Aqui temos um relance da prepotência humana, ou de um especismo. O próprio termo ambiente é condicionado ao organismo biológico. Por exemplo, chamamos um ambiente com baixa concentração de oxigênio, alta quantidade de matéria orgânica antropogênica e microorganismos nocivos à saúde humana: de um ambiente degradado. Porém, dificilmente, uma população de bactérias anaeróbicas "acharia" o mesmo desse "rico" ambiente.

${ }^{13}$ Cronon, William (ed.). "A place for stories: nature, history and narrative." The Journal of American History 78, 4, (1992): 1347-1376.
} 
um sentido ecológico, onde sociedade e natureza são coautoras de uma história conjunta. A premissa é que as ações humanas ocorrem dentro e através de uma rede de interações, processos e sistemas que são tanto ecológicas quanto sociais e culturais. E dependendo da maneira em que efetuamos nossas escolhas retóricas, metodológicas e teóricas, estaremos situando de diferente maneira em nossas narrativas os incluídos e excluídos, 0 relevante e 0 irrelevante, quem possui e quem não possui poder. ${ }^{14}$

Apoderar-se de uma escrita historiográfica que busque compreender as relações entre natureza e sociedade não significa simplesmente escrever uma história social juntamente com uma história natural de um ambiente. Uma das características da história ambiental sustenta que incorporar, interdisciplinarmente, ferramentas epistemológicas de diferentes áreas, como ecologia e geografia, possibilita analisar as relações entre a dimensão humana (social, cultural, político, econômico) e a dimensão natural (clima, vegetação, fauna, solo), sem perder de vista suas interseções como nossa materialidade corporal (fome, vícios, doenças, desejos e vontades), 0 trabalho humano no ambiente biofísico (agricultura, indústria, construção), mudanças na paisagem, entre outras. Em suma, compreender que o social não pode ficar a margem das relações da espécie humana com o restante da natureza. ${ }^{15}$ A apropriação do social e do natural de forma antagônica não permite perceber que a premissa fundamental é que as ações humanas ocorrem dentro e através de uma rede de interações, processos e sistemas que são, ao mesmo tempo, ecológicos e culturais. Numa tentativa de aproximar as ciências da natureza e as ciências sociais, incorporo o termo trabalho presente na obra de Marx. Segundo ele,

\begin{abstract}
Antes de tudo, 0 trabalho é um processo entre o homem e a Natureza, um processo em que o homem, por sua própria ação; media, regula e controla seu metabolismo com a Natureza. Ele mesmo se defronta com a matéria natural como uma força natural. Ele põe em movimento as forças naturais pertencentes a sua corporalidade, braços e pernas, cabeça e mão, a fim de apropriar-se da matéria natural numa forma útil para sua própria vida. Ao atuar, por meio desse movimento, sobre a Natureza externa a ele e ao modificá-la, ele modifica, ao mesmo tempo, sua própria natureza. ${ }^{16}$
\end{abstract}

No caso de categorias históricas, como classe, raça e gênero, acrescentar um vocabulário que ressalte entidades não humanas (vento, plantas, etc.) evidencia diferentes aspectos de coautoria na história. De um modo geral, as narrativas históricas tentam dar sentido numa realidade cronológica desordenada. Do ponto de vista da história ambiental, ao criarmos uma trama sem tal visão dicotômica, damos uma unidade que nem a natureza nem o passado possuem tão claramente.

Os rios urbanos do século XX são criações humanas, mas também possuem "vida própria" que existem fora de nosso controle. Conforme as cidades cresceram no entorno destes, modificaram seus cursos e suas margens, transformaram também suas relações e suas idiossincrasias. ${ }^{17}$ A cresceñte e incontrolável demanda pela água tem sido um fator comum na mudança de paisagem dos rios, o que tem levado a uma rédistribuição de poder e 0 surgimento de novas elites. ${ }^{18}$ Richard White ${ }^{19}$ escreve em Organic Machine sobre uma perspectiva pertinente para trabalhar essa realidade híbrida e complexa dos rios urbanos. Diferente da posição de Blaine Harden ${ }^{20}$ que aposta na morte do rio como uma história de lamento, White ressalta a pertinência em se distanciar

\footnotetext{
${ }^{14}$ Cronon, 114.

${ }^{15}$ Castro Herrera, Guillermo. Presentación. In Donald Worster. Transformacciones de la Tierra: Una Antologia Mínima de Donald Woster. Panamá, 2000; Gallini, Stefania. Invitación a la Historia Ambiental. Revista Tareas, v. 120, p. 5-28, 2005.

${ }^{16}$ Marx, Karl. O Capital: Crítica da economia política (Volume 1). São Paulo: Editora Nova Cultural, 1996. P. 297.

${ }^{17}$ Worster, Donald. Rivers of Empire: Water, Aridity, and the Growth of the American West. New York: Oxford University Press, 1992; White, Richard. The Organic Machine: The Remaking of the Columbia River. New York: Hill and Wang, 1995; Desfor, Gene; Jennifer Bonnell. Planning nature and the city: Toronto's Lower Don River and Port Lands. In L. Ander Sandberg, Stephen Bocking, Colin Coates, Ken Cruikshank. Urban Explorations: environmental history of the Toronto region. Ontario: Wilson Institute for Canadian History, 2013.

${ }_{18}$ Worster, 100; Swyngedouw, 2001.

${ }^{19}$ White, op. cit.

${ }^{20}$ Harden, Blaine. A river lost: the life and death of the Columbia. New York: London: W. W. Norton \& Company, 1996.
} 
de interpretações que considerem as modificações nos cursos d'água pela engenharia como causa de seu extermínio, ou perda. Em sintonia com White, William Cronon ${ }^{21}$ ressalta que as narrativas sobre o mundo biofísico têm levado a duas modalidades que tendem a ser mais simplistas: uma de progresso do homem sobre as falhas da natureza em suprir recursos; e outra de declínio da natureza frente às atividades humanas, e a ineficiência dos atores humanos em se adaptar ao ambiente estudado.

Vejamos por exemplo, a história do rio Berquó, que originalmente passava onde hoje é a rua General Polidoro e que tinha sua foz na Enseada de Botafogo. Após intensas modificações estruturais, desde o final do século XIX, encontra-se atualmente quase todo subterrâneo, com seu corpo d'água extremamente poluído, e com sua foz deslocada e cimentada. Uma história comum a quase todos os rios urbanos cariocas, exceto pelo fato de que poucos conhecem o rio Berquó atualmente. Na reconstrução histórica desse rio é possível optar por vê-lo de diferentes maneiras. Este relato pode ser uma prova do sucesso humano sobre a natureza, que o canalizou, ordenou, racionalizou, tornando-o parte da estrutura urbana de escoamento de água. Ou é possível construir uma narrativa em que se sublinha o fim das propriedades naturais "originais", em particular as que exaltam beleza cênica, declarando-0 um rio "morto", extinto, uma vala. Mas, podemos também escrever uma história de transformação, onde as dimensões naturais e sociais interagem e se influenciam mutuamente. E se qualificarmos o rio Berquó por algum adjetivo de insalubridade, teremos de observar de que maneira esta se mescla com os diversos aspectos sociais, em particular o comportamento humano.

Por tanto, o termo natureza passa a ser um obstáculo para compreender a inserção da atividade da espécie humana ao longo do tempo e do espaço. Nesse sentido como podemos evitar a dicotomia natureza-sociedade? De modo a entender os vários aspectos de natureza e mostrar como estão entranhados na experiência humana. Em vez de usar simplesmente a palavra natureza, ou natural, favorecemos termos que correspondam ao nosso interesse de incorporar tantos elementos humanos como não-humanos. Ao descrever diferentes ambientes do coletivo social para a narrativa de rios urbanos, venho utilizando termos como: ambiente biofísico para ressaltar aspectos não humanos, como velocidade do rio, sedimentos, calor da cidade, chuvas e secas; ambiente social para evidenciar aspectos da sociedade humana, como trabalho, tecnologia, discursos; por fim o termo ambiente sociobiofísico utilizado para explicitar o entrelaçamento entre essas duas dimensões que por vezes serão, inconvenientemente, separadas tanto na historiografia tradicional quanto aqui. Desta forma, 0 ambiente social que influenciou 0 amadurecimento da profissão dos engenheiros na capital do Império, por exemplo, precisam estar em sintonia com 0 ambiente biofísico e seus materiais para construção - como as pedras da Pedreira de São Diogo e ou a areia e barro extraído dos rios. No entanto, o termo ambiente sociobiofísico irá aparecer conforme 0 objetivo de ressaltar tais interações.

Desta maneira, a narrativa fica mais robusta com análises das complexas relações entre o ambiente biofísico urbano e a sociedade carioca reafirmando a presença humana na natureza e a influência desta ao longo do tempo, em vez de uma historiografia unidirecional de declínio ambiental, onde as modificações ambientais nos rios seriam determinantes em sua deterioração e "morte". Estas comparações, diz White, contribuem pouco para 0 entendimento de como os seres humanos alteraram os rios, e, em resposta, como os rios modificados alteraram 0 cotidiano social. ${ }^{22}$ De modo a ressaltar a importância dos rios nos inspiramos também na obra de Klingle ${ }^{23}$ que interpretou o papel ativo dos rios, suas atividades e movimentos que forçaram a sociedade a fazer escolhas do ponto de vista moral e político, como: construir ou não barragens, desviar cursos, etc. Embora o rio urbano não seja um agente, um personagem consciente na história, e tenha perdido grande parte das funções ecológicas naturais, considera-se os rios urbanos atuais tanto como construtos sociais que possuem uma história comum a ser investigada, como entidades autônomas, ainda que não independentes, que realizavam atividades fora do controle humano. ${ }^{24}$

\footnotetext{
${ }^{21}$ Cronon, op. cit.

22 White, 1995

${ }^{23}$ Klingle, Matthew. Emerald City: An Environmental History of Seattle. New Haven \& London: Yale University Press, 2007.

${ }^{24}$ White, 1995; Cronon, 1992.
} 


\section{Os fluxos dos rios e da história: diferentes maneiras de vermos os rios urbanos na historiografia}

Ao ver a história como provida de sentido - claro que incluo aqui questões infindas sobre como lidar com fontes e o modus operandi do historiador - podemos mirar para diferentes atores, sejam eles pequeninos grãos de argila ou engenheiros renomados, e ressignificá-los. Seguindo algumas possibilidades presentes na existência de grão de argila, vemos sua presença em sua gênese geológica, e como através do transporte fluvial alcança diferentes extensões. Seja como componente do solo para o plantio de mudas de café nos morros cariocas do início do século XIX, como elemento fundamental de tijolos e telhas presentes em toda a malha urbana, ou como substrato da lama dos mangues onde pescadores e catadores de caranguejo asseguram a fonte proteica nos seus pratos de comida. 0 que está em questão é conceber a argila conectada à realidade do mundo biofísico, juntamente às circunstâncias sociais. Os sedimentos aluviais depositados conforme a velocidade fluvial diminui, por exemplo, permitem tanto uma reordenação do fundo do rio que implica em diferentes interações como sua navegação, ou uma revitalização na agricultura. Estas modificações cedo ou tarde atingem os pratos de comida de parte da população e, claro, a economia dos pequenos agricultores. Vemos aqui que o modo como descrevemos e entendemos a natureza está tão emaranhado com nossos próprios valores e pretensões que os dois não podem ser separados totalmente. ${ }^{25}$ Apresento, então, algumas perspectivas possíveis para história dos rios e suas bacias hídricas.

Podemos vê-los, primeiramente, como cenário do teatro humano, numa perspectiva passiva, onde nos banhamos, pescamos, moramos e os usamos. 0 rio é o "onde", o lugar em que a história acontece, onde diferentes grupos indígenas desenvolveram o costume de banhos diários, onde os portugueses desviavam as águas para a agricultura exportadora ou de consumo, onde as fábricas esfriavam seus motores. Nessa perspectiva é possível ver também as desigualdades sociais decorrentes das apropriações e transformações. ${ }^{26}$ Sendo os rios meramente "lugar", passivos, esta passividade fluvial permite que um grupo adquira privilégios a partir da exploração social e ambiental, como na construção de barreiras para hortas, indústrias, hidrelétricas. Isto implica consequências sociais que vão do simples incômodo do rio Maracanã represado para benefício de uma grande horta de comércio a menos de 200 metros do que hoje é o núcleo comercial da Grande Tijuca: a Praça Saens Peña27; até a desapropriação de diversas famílias em áreas a serem alagadas para abastecimento d’água de um grande centro urbano.

Numa tentativa de contrapor esta perspectiva, sem, no entanto, excluí-la nem depreciá-la, podemos considerar os rios também como protagonistas, numa perspectiva ativa. Não se sugere aqui que os rios são agentes dotados de consciência de seus atos. Mas, sim que possamos perceber que o rio é mais que "lugar", ele também "faz acontecer". Este panorama ativo do rio é fundamental para que possamos refletir sobre a dimensão de sua importância para a sociedade. Baseado nas proposições dos historiadores que pesquisam sobre rios urbanos, ${ }^{28}$ compreendemos que esses possuem uma influência ativa na sociedade, como fatores essenciais na dinâmica e desenvolvimento da cidade. Os rios urbanos são considerados tanto sob a perspectiva descritiva rios que correm pelas cidades - assim como num sentido analítico - em que esses rios são imbricados nos processos de urbanização. ${ }^{29} \mathrm{~A}$ interação dos rios com a cidade possui relações próprias que são distribuídas de forma heterogênea no seu curso, apresentando diferentes causas e consequências de acordo com as circunstâncias históricas e particularidades locais.

Portanto, não faz sentido buscar essa abordagem se não for voltada para as características da temporalidade e espacialidade dos rios, os quais são considerados tanto para a perspectiva ativa quanto passiva. A temporalidade é um aspecto inerente ao trabalho do historiador, onde ponderamos sobre as mudanças e permanências das

\footnotetext{
${ }^{25}$ Cronon, William (ed.). Uncommon Ground: Rethinking the Human Place in Nature. New York: W. W. Norton \& Company, Inc., 1996.

${ }^{26}$ Worster, 1992.

${ }^{27}$ Documento BR RJ AGCRJ 49.4.95, Rios e Riachos: Catumby, Coqueiros, Maracanã, Trapicheiros, Joanna, Andarahy, Comprido, e outros de menor curso e volume de água, do Arquivo Geral da Cidade do Rio de Janeiro. Arquivo Geral da Cidade do Rio de Janeiro.

${ }^{28}$ Mauch, Christof; Zeller, Thomas. Rivers in History: Perspectives on waterways in Europe and North America. Pittsburg: University of Pittsburg Press, 2008; Evenden, Matthew; Stéphane Castonguay. Urban Rivers: Remaking Rivers, cities and space in Europe and North America. Pittsburgh: University of Pittsburgh Press, 2012.

${ }^{29}$ Evenden e Castonguay, 2012.
} 
sociedades. Isso com o intuito de não limitar essa percepção do espaço no tempo de modo estático, onde diferentes estruturas são vistas como produtos acabados. 0 que vale para o trabalho do historiador é refletir sobre as minúcias do tempo e espaço, e percebê-Ios de uma forma dinâmica: a temporalidade de curta e longa duração de Braudel é um bom exemplo dessa percepção dinâmica. ${ }^{30}$ Dessa maneira as relações não estão engessadas, mas sim, em constante transformação e adaptação entre os diferentes elementos que as compõem.

No caso dos rios, os diferentes regimes de chuva podem elevá-los alagando toda a região do vale, criando lagos temporários, mudando a conformação das rochas das cachoeiras. Após um período de seca, os rios, muitas vezes, têm seu curso original transformado, modificando aspectos diversos da sociedade, como, por exemplo, 0 limite entre dois terrenos ou de áreas cultiváveis. Ou seja, as mudanças nos rios acarretam alterações econômicas e culturais, no complexo processo do que estamos chamando de socionatureza urbana. Conforme essas mudanças vão ocorrendo, novas interações podem se desenvolver, assim como as velhas sucumbir. Já que tais mudanças sociais geralmente ocorrem no ritmo das modificações do mundo biofísico, é mais provável captar tal essência no âmbito da longa duração. Seja através de um estudo histórico ambicioso de alguns séculos, ou pela comparação de estudos pontuais de uma mesma localidade. Isto amplia um pouco mais a filosofia de Heráclito sobre não ser possível nos banhar nas mesmảs águas de um rio, mas o próprio rio já não é; ele está sendo.

Outro aspecto relevante é a percepção de que os rios variam ao longo do espaço. A sua rede hidrográfica se expande além dá bacia possibilitando interfaces diversas e heterogêneas com a cidade, e os diferentes aspectos ambientais e consequentes problemas urbanos. Diferentes localidades propiciam diferentes interações, ou seja perto da foz existem circunstâncias sociais e ambientais que são diferentes dos arredores da nascente do mesmo rio. As coletâneas de Mauch e Zeller ${ }^{31}$ sobre rios europeus e de Sandberg ${ }^{32}$ sobre rios canadenses, fornecem diferentes histórias comparativas de rios e cidades, que possibilitam compreender homem e natureza, assim como tecnologia e ambiente, como um contínuo. Para estes a paisagem natural importa para a cidade, influenciando-a e moldando-a, no entanto sem determinar o destino da sociedade.

Em relação à espacialidade fluvial, concebemos uma caracterização das bacias hídricas em três conjuntos geográfico-históricos, ou seções de: alto curso, com maior fluxo de água devido à maior inclinação e altitude; médio curso, onde o fluxo perde a força devido à menor inclinação e aos efeitos do atrito com o fundo do rio, e aumenta seu volume de água decorrente de outros mananciais; baixo curso, seção de planície, perto da foz, em que, naturalmente, o volume é bem maior e possibilita a formação de caminhos sinuosos chamados de meandros. É nesta seção onde ocorre as planícies de inundação, ou várzeas.

A principal variável que está em questão aqui é a velocidade do rio, que implica em outros fatores como 0 tamanho e suspensão dos sedimentos, grau de erosão das margens, etc. Ao longo deste gradiente de perda de inclinação e velocidade, o rio perde força para transportar os sedimentos. Ou seja, nas partes mais altas, com maior fluxo, os sedimentos menores entram em suspensão, não são depositados, e descem rio abaixo. Conforme a força diminui, os sedimentos menores vão precipitando no fundo do rio. Dessa maneira é de se esperar que 0 tamanho do sedimento no baixo curso (silte e argila), seja menor do que o do médio curso (areia) e do alto curso (cascalho e pequenas rochas). Ao longo da descida do rio acaba por ocorrer uma transição de locais de maior erosão, devido a velocidade e força da água, para outros de menor erosão e maior acumulação de sedimentos. Essa diferença implica na estrutura do rio e suas mudanças naturais como a erosão e assoreamento, a distribuição vegetal de florestas de mata atlântica nas partes de alto e médio curso, e manguezais e restingas nas de baixo curso. Assim como na utilização econômica das áreas das bacias hídricas, como por exemplo: a captação de água para consumo no alto curso, já que a carga de sedimento erodido é menor, e é possível transformar a energia potencial da gravidade para transportar a água para locais mais distantes; para indústrias no médio curso, que necessitam de áreas planas para suas construções; as áreas agrícolas do baixo curso, que necessitam de grãos menores que aumentam a capacidade de absorção de nutrientes, e também acabam por receber material orgânico e mineral de todo o rio.

As mudanças estruturais decorrentes de atividades sociais (represas, desvios, canalização, retilinização, perda da cobertura vegetal, etc.) interferem diretamente na dinâmica dos rios, modificando volume de água, velocidade, taxa de saturação de oxigênio, etc. Se considerarmos uma dessas variáveis para explorar as

\footnotetext{
${ }^{30}$ Braudel, Fernand. Escritos sobre a história. São Paulo: Editora Perspectivas, 2005.

31 Mauch e Zeller, 2008.

32 Sandberg et al, 2013.
} 
consequências no ambiente urbano, como a quantidade de oxigênio dissolvida na água, veremos que uma cadeia de consequências se desenvolve. Uma das causas recorrentes de uma baixa quantidade desse gás na água é seu consumo por bactérias. Um cenário bastante comum ocorre nas seções de baixo curso, onde 0 aporte de matéria orgânica - principalmente de esgoto doméstico -, a baixa circulação de água, a maior temperatura - devido ao acumulo de energia térmica ao longo dos rios e pelo atrito da água no fundo destes - possibilita a proliferação de bactérias anaeróbicas que consomem tanto a matéria orgânica quanto o oxigênio. 0 resultado desse metabolismo bacteriano são gases sulfídricos com a essência forte característica de ovo podre que ocorriam, e ainda ocorre; nos mangues cariocas. Todos esses fatores biofísicos se conectam no metabolismo da própria cidade, seja pela entrada no sistema-rio de matéria orgânica, ou pela saída dos gases malcheirosos. ${ }^{33}$

Ao combinarmos as ideias de temporalidade com as de espacialidade aplicadas no entendimento das relações entre a cidade e os rios urbanos, propomos uma reflexão mais profunda e complexa de eventos pontuais. Como episódios de ex̃tremos de pluviosidade e suas consequências (enchentes, cabeças d'água, deslizamentos de terra), e eventos a médio e longo prazo, derivado de transformações de origem natural (modificação na desembocadura dos rios, alterações nos meandros do baixo curso, gerando mais áreas de alagadas) e antrópicas (canalização, aterro, drenagens, pontes). Dessa maneira, diversos personagens atuam conjuntamente na construção da paisagem socionatural urbana do Rio de Janeiro, como: o Estado, e seu corpo de engenheiros que através de diferentes tecnologias são os principais interventores das modificações nos rios urbanos; as indústrias, basicamente têxteis, que em menor escala alteram estruturalmente os rios, porém intervindo de maneira diferente e mais sutil do que outros grupos; e a população local, que com suas idiossincrasias apresenta inúmeros comportamentos frente aos corpos d'água desta tese.

\section{Os rios e as cidades: recosturando o tecido socionatural}

A natureza gira, de fato, mas não ao redor do sujeito-sociedade. Ela gira em torno do coletivo produtor de coisas e de homens. 0 sujeito gira, de fato, mas não em torno da natureza. Ele é obtido a partir do coletivo produtor de homens e de coisas. 0 Império do Centro se encontra, enfim, representado. As naturezas e sociedades são os seus satélites. ${ }^{34}$

As relações sociais operam metabolizando o meio ambiente "natural" através do qual tanto a sociedade quanto a natureza são transformadas e novas formas socionaturais são produzidas. ${ }^{35}$

Possivelmente a ideia de imbricamento entre natureza-sociedade esteja melhor exemplificada nos trabalhos de Erik Swyngedouw, que define a cidade, em particular, como uma coisa híbrida, simultaneamente natural e social, mecânica e orgânica: Insistir na transcendência de binarismos através de linguagens e neologismos que mantenham a dialética do processo relacional permite um melhor entendimento e construção de uma narrativa dos processos e interações. ${ }^{36}$ Socionatureza ${ }^{37}$ é um termo conveniente que parece ter amenizado 0 abismo entre o natural e 0 social nos estudos urbanos. Para Swyngedouw, "o processo de produção da socionatureza inclui processos materiais (edifícios e novos materiais genéticos) bem como múltiplas representações simbólicas e

\footnotetext{
${ }^{33}$ Schäfer, Alois. Fundamentos de ecologia e biogeografia das águas continentais. Porto Alegre: Ed. da Universidade, UFRGS, 1984.

${ }^{34}$ Latour, 78.

35 Swyngedouw, 86.

${ }^{36}$ Latour, 1994 e Swyngedouw, 2001.

${ }^{37}$ Embora o termo proponha uma união entre sociedade e natureza, ele opera etimologicamente com a raiz das duas palavras. A proposta é a de efetivamente reconhecer uma dicotomia e, a partir disso, apoderarmos de conceitos que atuem nessa união.
} 
discursivas da natureża" ${ }^{38}$ Essa mistura conceitual que consiste a cidade permite situá-las nem exclusivamente como objetos, nem como sujeitos, mas sim como quase-objetos. E conforme vamos desvendando as redes traçadas através deles, e por eles, percebemos que os quase-objetos nos aparecem "algumas vezes como coisa, outras como narrativa, outras ainda como laço social, sem nunca reduzir-se a um simples ente". ${ }^{39}$

Assim, elementos materiais como areia e argila, que são metabolizados e incorporados na dinâmica da construção de edifícios nas cidades, passam a dar mais sentido às transformações socioecológicas que ocorrem dentro e fora delas. No estudo de Swyngedouw, 0 autor adota como objeto o termo água, conforme comentado no início deste texto. Subscrevo, como ele, que sem a "domesticação" da circulação da água pelas tecnologias de engenharia sanitária, por exemplo, o desenvolvimento urbano não ocorreria da mesma maneira como o vemos hoje. Essa circulação potencializa e complexifica as interações dentro do tecido socionatural urbano, criando oportunidades, por exemplo, para mais residências e indústrias, e menos doenças. Mais água transitando permite mais abastecimento de água, mais escoamento dos dejetos industriais e humanos, mais oferta para esfriamento de motores e geração de energia por hidrelétricas. Porém, reitero que, para este trabalho, tratar como objeto de estudo os rios urbanos, em vez da circulação de água, possibilita uma maior materialidade dos comportamentos sociais e naturais no fluxo e nas margens destes corpos d'água. 0 que de certa maneira contribui para 0 entendimento de aspectos culturais dos rios urbanos no cotidiano do povo que possui como gentílico o mesmo nome de um de seus rios: Carioca. Assim, buscando a espacialidade e materialidade da circulação das águas urbanas através dos rios urbanos, possibilitaria uma narrativa que contemple diferentes personagens que possivelmente seriam esquecidos: pescadores e barqueiros, empresas que extraem areia dos rios, pequenos agricultores que desviam os cursos, mobilizações sociais contra modificações fluviais estruturais que prejudiquem localmente, etc.

Em vista disso, torna-se interessante apropriarmos das três dimensões propostas por Donald Worster. ${ }^{40} \mathrm{~A}$ primeira trata do entendimento da natureza propriamente dita, como esta se organizou e funcionou no passado. Trata-se de ressaltar os aspectos e processos naturais que a sociedade também está sujeita, como: épocas de estiagem, chuvas torrenciais, enchentes, etc. A segunda insere o domínio sócio-econômico na medida em que este interage através do ambiente. No caso deste estudo, a tecnologia fica evidente aqui como atuação humana que está frente a essa interação com o ambiente. Como uma releitura do conceito marxista de modo de produção, esta dimensão permite compreender como os diversos ambientes naturais influenciaram o surgimento de novas tecnologias. Dessa maneira, torna-se interessante para enriquecimento da análise indagar quais grupos ganharam ou perderam poder quando estes modos de produção mudaram, de modo a reforçar o fato de que 0 uso da tecnologia não é neutro, sendo esta engajada com questões políticas. Por fim, de modo a entender padrões comportamentais que influenciem as atividades de transformação da natureza, a terceira dimensão existe no campo mental, cultural, considerando as percepções, leis, mitos, valores éticos. Embora essas dimensões estejam disponibilizadas distintamente para efeito de clareza argumentativa, na realidade elas são consideradas um único conjunto dinâmico de investigação. ${ }^{41}$

Interessante notar aqui que Worster apresenta os elementos constituintes do passado histórico categorizados de uma maneira que não se pretende explorar aqui. Para ele, a ideia de natureza construída (builtenvironment), categoria em que as cidades são bons exemplos, é uma expressão integral da cultura humana. 0 historiador Martin Melosi, ao ponderar sobre o trabalho de Worster, afirma que um dos problemas nessa afirmação da cidade exclusivamente humana, social, é que seria possível existir também uma natureza intocada, pura, sem intervenção humana alguma. A abordagem que tenho desenvolvido aqui não permite nenhuma dessas duas considerações extremas sobre natureza e sociedade. Pelo contrário, a socionatureza permite a cidade como um híbrido nesta dicotomia. Preferimos para o passado urbano uma definição em que características físicas e sociais influenciam e se moldam por forças naturais, crescimento e desenvolvimento urbano, mudanças espaciais e ação humana. 42 Uma concepção que se adequa bastante à história da cidade do Rio de Janeiro, onde seu crescimento e desenvolvimento estiveram dependentes e limitados por aspectos topográficos como rios, montanhas e litoral.

\footnotetext{
${ }^{38}$ Swyngedouw, 88.

${ }^{39}$ Latour, 87.

${ }^{40}$ Worster, Donald. Para Fazer História Ambiental. Estudos Históricos 4(8), 1991.

${ }^{41}$ Worster, 1991.

${ }^{42}$ Melosi, Martin. "The Plaçe of the City in Environmental History." Environmental History Review 17,1 (1993):1-23..
} 
Após esclarecer que a cidade e seus sistemas constituem uma rede de processos humanos e naturais entrelaçados e inseparáveis, entramos em conflito com as possibilidades instrumentais de realmente estudá-los. Dependendo do objeto de estudo, diferentes áreas do conhecimento podem contribuir mais ou menos para a investigação. Perspectivas com olhares mais específicos certamente contribuem para o enriquecimento dos resultados da análise histórica, mas as limitações humanas do historiador devem nortear a escolha de temas mais afins ao objeto de estudo: tecnologia, cultura, comportamento humano, meteorologia, grandes intervenções na paisagem, influência da mídia. Podemos pensar em diversos sistemas de interações com diferentes níveis de complexidade: biológico e sociocultural. Esses sistemas estão imbricados, porém não faz sentido analisar o social do ponto de vista estrito das ciências biológicas. Embora possa ser interessante nos apropriarmos de algumas noções mestiças derivadas originalmente de áreas de estudo aparentemente desconexas com nosso objeto de estudo. Embora as possibilidades de combinação interdisciplinar sejam praticamente infinitas, existem ferramentas epistemológicas que abrangem diferentes campos de estudo. Ressalto aqui conceitos que permitam analisar as múltiplas interações que compõe a socionatureza que permeia os rios urbanos cariocas, 0 de acoplamento de Maturana e Varela (2001), e 0 de rede sociotécnica de Latour. ${ }^{43}$

Ao estudar sobre as bases biológicas do conhecimento humano, os chilenos Humberto Maturana e Francisco Varela ${ }^{44}$ desenvolveram 0 conceito de acoplamento voltado para 0 entendimento de diferentes níveis de organização da complexidade biológica:45 estrutural, comportamental, linguístico e social. Originalmente entendido para a relação do indivíduo biológico em seu meio natural, o acoplamento é um processo mútuo onde o organismo e o meio sofrem transformações, uma expressão de uma dinâmica estrutural provocada por interações. Esta ideia se contrapõe ao antigo conceito unilateral de adaptação, onde o ambiente mantém-se estático e somente 0 organismo se modifica. 0 acoplamento permite observar as interações entre indivíduo-meio, e também entre indivíduos. As possibilidades estruturais, comportamentais, de linguagem ou sociais, estão vinculadas ao acoplamento e sua plasticidade. A transposição deste conceito para a narrativa histórica deve ser atenta a limitações e deturpações. Tudo acontece num momento, num lugar (meio). Ao pensar sobre lavadeiras usando a água de um rio, elas estão acopladas a este meio neste momento, de diferentes maneiras. Semelhantemente, um comportamento de um vendedor de água ou de um banhista está intimamente ligado à qualidade de consumo da água; para entender o comportamento dos dirigentes de uma fábrica de tecidos temos de considerar tanto 0 rio quanto 0 cenário político. Ao modificar 0 ambiente, é bem provável inviabilizar um comportamento específico, o que significa em buscar outro local - outra fonte de água -, ou mudar 0 comportamento - buscar outra fonte de renda.

A própria saúde, humana e ambiental, também se insere nesse aspecto de acoplamento, em particular 0 estrutural e o comportamental. Isso fica mais evidente se nos atentarmos nos hábitos alimentares e de trabalho, como por exemplo, os carvoeiros. As carvoarias do século XIX localizavam-se principalmente nas partes altas dos morros, oferecendo lenha e carvão para milhares de fornos residenciais e industriais. 0 modo em que 0 trabalhador está condicionado, por si, por seus superiores, e por condições culturais, influenciā tanto a intoxicação de seu pulmão, o prejuízo ergométrico de sua coluna, modificando severamente sua vitalidade; quanto a estrutura da floresta, que após desmatada transforma a dinâmica do solo, exportando uma grande quantidade de sedimentos que descem rio abaixo, e também diminuem sua capacidade de reter água e reabastecer as bacias hídricas.

A questão é ver as idiossincrasias, os detalhes e riquezas de uma maneira simétrica. Além de enriquecer, esta abordagem evita terraplanar questões de gênero, raça e classe, muitas vezes exposta numa narrativa simplificada e injusta, dando maiores ênfases na diversidade das interações e não somente nos personagens. Como pensar 0 acoplamento estrutural entre cidades e rios? A própria expansão urbana parece ser melhor entendida nesse aspecto, pois existem forças do mundo biofísico que moldam as possibilidades de crescimento

\footnotetext{
${ }^{43}$ Latour, op. cit.

${ }^{44}$ Maturana, Humberto; Varela, Francisco.A Árvore do Conhecimento: as bases biológicas da compreensão humana. São Paulo: Palas Athena, 2001.

${ }^{45} \mathrm{O}$ uso de termos da biologia no entendimento da cidade tem ocorrido desde muitos séculos. Inicialmente utilizando o termo circulação, com clara influência das descobertas da dupla circulação sanguínea no corpo humano feitas por William Harvey. Em um segundo momento, as ideias de organismo e metabolismo são incorporadas nas ciências sociais do século XIX, em especial por Karl Marx. Seja por comparações pertinentes como estas, ou "infelizes" como a evolução urbana proposta pelo darwinismo social, a apropriação de termos biológicos não é nenhuma novidade (Sennett, 2003 e Melosi, 1993).
} 
da cidade, como oferta de água, limitação topográfica (morro, praia, etc.). Assim como há forças sociais (tecnologia, política, obras públicas, etc.) que também moldam as possibilidades do crescimento urbano, assim como modificam o ambiente, e consequentemente remoldam as possibilidades das forças do mundo biofísico. Aqui podemos nos apropriar de termos que já são comuns à prática historiográfica como contexto, circunstâncias sociais, cenários culturais.

0 acoplamento vira então uma construção histórica desses híbridos, quase-objetos, considerando para isso que suas interações adquiram um caráter recorrente, ou muito estável. "0 resultado será uma história de mudanças e concordantes, até que a unidade e 0 meio se desintegrem", ${ }^{46}$ e fique em evidência a hibridização, 0 sujeito composto. Sob esta ótica, o estudo da cidade como um todo, como um sistema completo, não faz sentido se não considerarmos os elementos externos à ela, como: comida, água, eletricidade, produtos, etc. Da mesma maneira, ao ter como horizonte a compreensão da historicidade de rios urbanos, é preciso captar aspectos que também escapam à espacialidãde urbana: bacias hídricas, clima local, aspectos culturais que influenciaram decisões de obras públicas, aspectos econômicos e tecnológicos que moldaram atividades fabris, etc. As transformações na socionatureza urbana gera, por sua vez, mudanças estruturais nos rios urbanos, mudanças comportamentais e sociais nos diferentes grupos envolvidos, evidenciando uma complexa espiral de causalidades que é extremamente difícil de elaborar uma escrita histórica. 0 conjunto desses acoplamentos certamente enriquece tal narrativa, mas o fio da meada só não se perde se contemplarmos a complexa rede por trás disso tudo.

Formada por fluxos, conexões, misturas, as redes possuem múltiplas entradas e saídas, onde todos são atores construindo-se mutuamente. Sendo "ao mesmo tempo reais como a natureza, narradas como um discurso, coletivas como a sociedade". ${ }^{47}$ Abordar estas interseções de maneira holística, que conectam e separam, de forma simétrica, significa expandir as possibilidades de estudo para novos agentes, novos cenários, novos objetos, sem perder de vista a posição do objeto de estudo nesse coletivo. Como podemos obter tais simetrias nos estudos de rios urbanos? Não basta somente salpicar contribuições sociais com explicações científicas sobre as forças naturais, é preciso um aprofundamento da análise do quase-objeto. Por exemplo, os rios urbanos, já considerados aqui como híbridos, foram profundamente modificados pelos planejamentos dos engenheiros no final do século XIX. 0 estabelecimento e a profissionalização desta classe estiveram fortemente associados com os mitos ${ }^{48}$ de progresso e de civilização que permearam diferentes ideologias desse momento. Diversas modificações estruturais em áreas consideradas insalubres foram resultado tanto das intervenções no mundo biofísico, quanto do coletivo de ideias que circularam o meio acadêmico de médicos e higienistas. Buscar a compreensão das atividades dos engenheiros e deixar de lado todo um complexo de ideias médicas que influenciaram gerações seria incompleto, além de ingênuo. Tampouco podemos deixar de lado os fatores sociais de abandono da estrutura estatal de saneamento básico nas áreas insalubres supracitadas, que tiveram forte influência em considerar tais locais como área de futura expansão urbana, em vez de bairros residenciais. Esses diversos acoplamentos afirmam a noção das múltiplas redes por trás dos rios urbanos, matizando resistências de grupos socialmente desprivilegiados e imposições de grupos socialmente privilegiados, o coletivo cultural de ideias que mobilizam tais grupos, a passividade e a intervenção do ambiente biofísico.

Como podemos operar com o coletivo de atores sociais nesse contexto de redes e interações? Como podemos delinear grupos, classes, instituições, quando tendemos a cair numa arbitrariedade? Ao meu ver o que 'colaria' esses indivíduos num grupo social e não num outro tem mais a ver com a narrativa do historiador, do que com a suposta 'realidade' social do passado. "Em cada momento, temos de reconstruir a concepção do que estava associado porque a definição anterior passou a ser, até certo ponto, irrelevante." ${ }^{9}$ Impor uma ordem que 'ensine' o que os agentes so ciais foram, ou buscar alguma consciência dos atos do passado, dificulta a observação e a análise das complexas interações.

Aqui as concepções construtivistas de Latour ganham força com a tradição estruturalista de Bourdieu, e sua teoria de campo. 0 campo, assim como as redes, é entendido através das relações, "não na vontade de um indivíduo ou de um grupo, mas sim no campo de forças antagonistas ou complementares (...)" . ${ }^{50}$ Relações sociais

\footnotetext{
${ }^{46}$ Maturana e Varela, 2001: 87

${ }^{47}$ Latour, 1994: 12

${ }^{48}$ Tomo aqui a ideia de mito conforme desenvolvido por Raoul Girardet. Girardet, Raoul. Mito e mitologias políticas. São Paulo: Companhia das Letras, 1987.

${ }^{49}$ Latour, Bruno. "Como prosseguir a tarefa de delinear associações?" Configurações 2(2006): 11-27.

${ }^{50}$ Bourdieu, Pierre. O poder simbólico. Rio de Janeiro: Editora Bertrand Brasil, 1989, p. 81.
} 
entre os indivíduos què compartilham interesses em comum, mas que não possuem os mesmos recursos, capital. "Os agentes e grupos de agentes são assim definidos pelas suas posições relativas neste espaço". ${ }^{51}$ Dessa maneira, as assimetrias e desigualdades sociais emergem na narrativa conforme compreendemos a dinâmica de poder entre quem possui mais recursos e quem possui menos. Portanto, os grupos seriam delineados, mesmo que limitado no tempo e no espaço, a partir de atitudes e interesses semelhantes que atuam num determinado campo (econômico, científico, simbólico, social). 0 que se busca é um espaço de relações, certamente conflituosas por um lado e cooperativas por outro, mediadas pelo habitus de seus atores.

$\mathrm{Na}$ presente proposta de narrativa de rios urbanos, os funcionários do Estado - burocratas, engenheiros, poder executivo -, que regulam quem pode, e de que maneira, se apropriar do ambiente biofísico, agem sobre um campo social em que também estão presentes outros grupos, como os participantes do jogo do capital econômico que possuem muitos recursos - cafeicultores, donos de hotéis e de fábricas, empresários diversos , e integrantes que possuem poucos recursos - lavadeiras, banhistas negros, moradores locais. Acompanhar os processos de busca e ganho de recursos (capital econômico, simbólico, etc.) por diferentes grupos permite compreender como desencadeou os diversos casos de desigualdades sociais, assimetrias do jogo de poder, decorrentes das transformações da socionatureza no decorrer do tempo.

0 complexo que constitui os rios urbanos no contexto da rede não está de forma alguma hierarquizado nem dicotomizado, suas conexões entre diferentes interações são múltiplas. Na realidade, cristalizar a noção de rios urbanos, com suas infinitas conexões considerando majoritariamente sua unicidade, leva a perder de vez a sua multiplicidade. Os elementos presentes nas redes, assim como a própria rede, não "é", mas "estão sendo". Eles se ressignificam, se transformam, ultrapassando a si mesmos. Podemos falar, assim como Deleuze e Guattari 0 fizeram ao defender 0 conceito de rizoma, que de certa maneira se assemelha ao de redes, sobre processos de territorialização e desterritorialização.

A orquídea se desterritorializa formando uma imagem, um decalque da vespa; mas a vespa se reterritorializa sobre esta imagem. A vespa se desterritorializa, no entanto, tornado-se ela mesma uma peça de aparelho de reprodução de orquídea; mas ela reterritorializa a orquídea, transportando o pólen. A vespa e a orquídea fazem rizoma em sua heterogeneidade. ${ }^{52}$

Voltando ao personagem engenheiro, seria imprudente desconsiderar toda sua heterogeneidade temporal e coletiva, suas transformações, sua territorialização e desterritorialização. 0 engenheiro André Gustavo Paulo de Frontin (1860-1933), por exemplo, possui peculiaridades em sua história que, sem estas, deixaria a narrativa capenga, como o episódio da Água em Seis Dias. No ano de 1889 após um período de estiagem e epidemias de febre amarela, a agitação de Rui Barbosa no Diário de Notícias acusando incompetência do governo imperial gerou comoção para a solução do constante problema de falta d'água no Rio de Janeiro, que mobilizou diversos engenheiros. Dentre as propostas para a solução estava a do professor da Escola Politécnica, Paulo de Frontin, que se responsabilizaria em desviar o rio Tinguá, e dois outros menores, por dezenas de quilômetros em apenas seis dias por um quarto da proposta mais barata. Dom Pedro II fora um dos poucos que apostaram na inacreditável proposta do jovem engenheiro, auxiliando-0 com dois trens da Estrada de Ferro Rio d'Ouro para transporte de materiais e pessoal. № dia 24 de março de 1889, após os referidos 6 dias e noites mal dormidas pelos trabalhadores, Frontin apresentara o resultado. José de Santa Ritta em Água do Rio53 narra os "Iouros" colhidos por Paulo de Frontin, que foi carregado pela população do ponto terminal da estrada de ferro Rio D'Ouro em São Cristóvão até a rua do Ouvidor. Assim vemos em Girardet ${ }^{54}$ que 0 mito é uma resposta a uma expectativa, uma exigência da sociedade, ou seja, que o processo de criação do herói implica na adequação entre a personalidade do salvador e as necessidades de uma sociedade num dado momento. A reação ao trabalho de Paulo de Frontin resultou em comemorações durante várias semanas, com bailes, luminárias pelas ruas, Te Deum, medal has comemorativas. ${ }^{55} 0$ mito nessas circunstâncias ganha amplitude e se estende na memória coletiva por mais tempo. Assim, após 50 anos, no mesmo jornal que lançara o desafio, entre os acontecimentos que antecederam a Segunda Guerra Mundial, havia a notícia da homenagem que a prefeitura do município de Paulo de Frontin e

\footnotetext{
${ }^{51}$ Bourdieu, 134.

52 Deleuze, Gilles, Felix Guattari. Mil platôs (volume I). São Paulo: Editora 34, 2000.

${ }^{53}$ Santa Ritta, José de. A água do Rio: do Carioca ao Guandu: a história do abastecimento de água da cidade do Rio de Janeiro. Rio de Janeiro: Synergia: LIGHT: Centro Cultural da SEAERJ, 2009.

${ }^{54}$ Girardet.

${ }^{55}$ Santa Ritta, op. cit.
} 
líderes da capital fedèral, no Rio de Janeiro, prestaram ao túmulo do "tão eminente brasileiro" ${ }^{56}$ A cidade se desterritorializa através das mudanças de suas dificuldades hídricas da segunda metade do século XIX, ela tornase sedenta. Não podemos simplesmente considerar qualquer engenheiro como ostentador da salvação da seca, já que muitos proporam soluções que não foram efetuadas, confiadas. Frontin se desterritorializa conforme 0 poder público (Imperador) confia em seu plano e investe nele, e se transforma num símbolo de esperança, e depois prosperidade, conforme seu plano deu certo. A materialidade e os aspectos culturais da cidade sedenta e a figura mítica do engenheiro salvador também constituem um rizoma em sua heterogeneidade. E nessa trama estão também os trabalhadores em regime semi-escravo, o desvio quilométrico do rio Tinguá, 0 alívio da população urbana sedenta, a mitificação da figura do engenheiro em sintonia com os ideias de progresso e civilização que transformaram cada vez mais a cidade. E, mais uma vez, "sem percepção clara da natureza da sua tarefa, ao construir a cidade 0 homem reconstruiu a si mesmo". 57

Neste episódio fica claro uma dimensão da cidade que não pode estar afastada de nossas investigações: a urbanização como fenômeno de classe, onde 0 excedente é extraído de muitos e o controle sobre sua distribuição é atribuição de poucos. Isto é, por si só, um processo urbano global em que ocorreu em diversas cidades americanas e europeias, como Paris, Nova York e Viena, reafirmando a urbanização como peça fundamental para a sobrevivência do capitalismo. As semelhanças nas circunstâncias sociais de tais cidades permitiram que as reformas urbanas tornassem necessárias, necessitando de um grande número de trabalhadores, instituições financeiras e instrumentos de débito, e claro um sistema de repressão violenta. ${ }^{58}$ Nessa perspectiva urbana progressista, baseada no racionalismo, na ciência e na técnica, o espaço da cidade busca se adequar aos conceitos de higiene e civilização e, em particular, de racionalidade. Assim a reordenação espacial torna-se rigorosa separando-se autoritariamente e distintamente em locais de trabalho, moradia, cultura e lazer ${ }^{59}$ Como vimos num exemplo mais acima, essa reestruturação urbana geralmente afeta mais, e de maneira violenta, os desprivilegiados e marginalizados pelo poder público, que geralmente são também associados como ameaça à ordem pública. Ainda no século XIX Friedrich Engels escreve:

Este é 0 denominado método "Haussmann"... Não importa 0 quão diferentes sejam as razões, o resultado é sempre o mesmo: escandalosas alamedas e ruelas desaparecem para exaltação e desperdício da burguesia por causa de seu extraordinário sucesso, mas elas reaparecem imediatamente em outro lugar (...). A mesma necessidade econômica que as produz num primeiro lugar, as produz em outro lugar. ${ }^{60}$

E assim, com tal "destruição criativa", a população carioca era expulsa dos cortiços presentes na seção de baixo curso dos rios urbanos, e seguia "caminho" rio acima, para constituir as primeiras favelas nos morros. E com o tempo, muitos migraram para as partes altas da seção de alto curso das mesmas bacias que haviam sido expulsos, criando, por exemplo, as favelas presentes no Estácio. Assim, modificaram seu cotidiano de pegar a água, descartar esgoto e lixo, se transportar, criando assim novas interações, novas transformações. Necessitando para tal, de novas histórias, novas narrativas.

\footnotetext{
${ }^{56}$ Extraído da página 5 do Diário de Notícias de 25 de março de 1989.

57 Park, 1967: 3

${ }^{58}$ Harvey, David. O direito à cidade. Lutas Sociais, São Paulo, n. 29, p. 73-89, jul./dez., 2012

${ }^{59}$ Choay, Françoise. O Urbanismo: Utopias e Realidades: Uma Antologia. São Paulo: Ed. Perspectiva, 1979.

${ }^{60}$ Engels, Friedrich. The Housing Question. New York: International Publishers, 1935, p. 74-77.
} 


\section{Considerações finais}

Esses diversos acoplamentos afirmavam a noção das múltiplas redes por trás dos rios urbanos, matizando resistências de grupos socialmente desprivilegiados e imposições de grupos socialmente privilegiados. 0 uso da terra por plantações de cafezeiros, extração de madeira, carvoarias, esteve vinculado com o desmatamento e a diminuição da vazão dos rios que abasteciam a cidade. Enquanto a classe dos engenheiros se desenvolvia institucionalmente no Rio de Janeiro, o discurso do governo imperial tendia para a centralização das atividades de interesse para 0 abastecimento d'água. A transformação de ecossistemas "sadios" em "não-sadios" comprometia suas funções ecológicas (oferta de água, ar puro, contenção de erosão) e a apropriação social (banho, lenha, caça). 0 papel da história aqui foi de construir uma narrativa que fosse sensível às transformações dessa socionatureza que possuía, ao mesmo tempo, questões sociais e ambientais que também foram transformadas de maneira mútua.

De maneira simplificada, ao buscar associações mais explícitas sobre 0 ambiente físico e 0 ambiente urbano, o modo como construímos nossas narrativas reflete sobre as maneiras que podemos compreender as interações entre os rios urbanos e o restante da cidade. Para tal, algumas posições foram pertinentes. Considerei que (1) os rios urbanos interagem de maneira ativa e passiva, direta e indiretamente, com e através de, a sociedade urbana. No entanto, isso não significa que os diferentes grupos sociais responderão da mesma maneira às adversidades ambientais. Esta heterogeneidade também pode ser vista nos rios e suas relações, pois que (2) a diversidade do ambiente físico permite, então, uma infinidade de relações entre este e as estruturas humanas. Ou seja, diferentes ambientes significariam também, diferentes relações, organizações. Assim, reconheço que a suficiência, ou a falta dela, de recursos dos grupos sociais são cruciais na resposta às mudanças no ambiente físico. Por fim, considerando (3) a presença, ou ausência, humana, o ambiente físico se modifica constantemente, gerando novas interações. Conforme 0 ambiente satura sua capacidade de resiliência, as relações sociais tendem a ser mais conflituosas.

Apesar de vivenciarem eventos de intensa modificação estrutural, os rios urbanos permanecem. Sujos, canalizados, mas não descaracterizados de sua essência fluvial, seus fluxos, suas quedas, sua foz. A proposta de narrativa buscando um híbrido urbano para esses cursos d'água buscou demonstrar transformações de um modo geral, tanto social quanto natural. A apropriação do termo socionatureza, em conjunto com as ferramentas epistemológicas apresentadas, forneceu meios para entender as complexas relações entre natureza e sociedade. Ao fim, a separação destes dois termos não parece proveitoso para um entendimento holístico do passado humano. Nossas atividades através do ambiente biofísico contempla mais do que os simples aspectos sociais e culturais. Foi preciso olhar para a água, para os sedimentos, para os movimentos. Diferentes personagens históricos são apresentados de maneira mais abrangente e rica. E tantos outros esquecidos, subestimados, simplificados, podem ter uma participação maior na construção historiográfica do passado coletivo humano. Espero que com a elaboração de narrativas que busquem repensar as diferentes maneiras das interações que constituem a socionatureza ao longo do tempo, permitam uma maior compreensão da historiografia do ambiente e da sociedade. E quem sabe, gerar mais perguntas, mais escolhas, e menos dicotomias. 